\title{
Extracellular RNA in renal diseases
}

\author{
Yang Zhou and Junwei Yang ${ }^{*}$ (D)
}

\begin{abstract}
The discovery of extracellular RNA (exRNA) in blood and bodily fluids has expended our knowledge on RNA functions. ExRNAs may be transferred between cells and have functional significance in health and diseases by horizontal gene regulation. Moreover, exRNA may serve as diagnostic biomarkers and therapeutic tools. Thanks to the evolving techniques, exRNAs, particularly those detected from urine have gained great interest in renal diseases. However, most current studies on exRNA in renal diseases were derived from limited numbers of patients or in vitro data. Recent isolation and detection techniques also remained controversial. Nonetheless, the reliable techniques are developing and improving. This review will provide insights into the roles of exRNA in pathogenesis, diagnosis and therapy of renal diseases.
\end{abstract}

Keywords: Extracellular RNA, exRNA, Renal, Vesicle, miRNA

\section{Introduction}

Many RNA species have been found in eukaryotic cells by interpretations of gene transcription within genomes. However, the discovery of RNAs outside the cells is more striking because of the assumption that high levels of RNAse in plasma and various body fluids will immediately destroy extracellular RNA (exRNA). Most exRNAs are either encased in extracellular membranous vesicles or formed complexes with lipids or proteins to avoid degradation. There are growing interests in exRNA over the past decade. With the development and improvement of isolation and detection tools that enable the discovery of exRNAs, researchers in nephrology have detected exRNAs in various body fluids, particularly blood and urine. Analysis of urinary exRNAs may serve as noninvasive and logical diagnostic and prognostic approaches. Moreover, the transitivity of exRNA information between cells suggests their functional and probably therapeutic roles in renal diseases. In this review, we will overview of the characterization of exRNA, summarize the current cognition about the role of exRNAs in renal diseases and compare the isolation and detection techniques.

\section{Characterize of exRNAs}

Given the levels of RNAse in extracellular spaces, RNA function is considered to be applicable only within the

\footnotetext{
* Correspondence: jwyang@njmu.edu.cn

Center for Kidney Disease, Second Affiliated Hospital, Nanjing Medical

University, 262 North Zhongshan Road, Nanjing 210003, Jiangsu, China
}

cells. However, with the assistance of highly sensitive tools, exRNAs have been discovered in bodily fluids, including plasma/serum [1], urine [2], saliva [3], breast milk [4] and semen $[5,6]$.

ExRNA defines a group of several types of RNAs exist in the extracellular environment, whose functions are diverse. The types of exRNA that have been found are as follows: microRNA (miRNA, miR), small interfering RNA (siRNA), messenger RNA (mRNA), transfer RNA (tRNA), long non-coding RNA (lncRNA), piwi-interacting RNA (piRNAs) and small nucleolar RNA (snoRNA) [7].

To avoid degradation, most exRNAs are either packaged within membranous vesicles, such as exosomes (40-100 $\mathrm{nm})$, shedding vesicles $(100-1000 \mathrm{~nm})$ and apoptotic vesicles $[8,9]$, or are associated with proteins or lipids.

Most studies have focused on exosomes as carriers of exRNA, the reasons may as follows: (i) recent RNA microarray studies were mainly performed from purified exosomes [10-12]. (ii) exosomes are endosomal origin vesicles that formed by invaginated multivesicular bodies (MVBs) and contain signaling concern endosomal transport within cytoplasm and fusion with plasma membrane [13], which means the export of RNA through exosome is highly regulated. Moreover, (iii) some RNAs are actively imported into MVBs during the process of intraluminal vesiculation, since the localization of miRNAs processing RISC machinery to the surface of MVBs [14, 15] and the decrease in miRNA secretion by inhibition of ceramide synthesis 
[16-19]. However, how longer RNAs, particularly mRNAs or lncRNAs are specifically export into exosomes is quite unclear.

Although multiple types of RNAs were detected by microarrays and RNA sequencing experiments, the abundance of full-length mRNAs and whether they have biological activities remain uncertain. It is also unknown whether there is a size threshold for lncRNAs. Recently, Ben-Dov et al. demonstrated that urine-derived extracellular vesicles were enriched with plenty of miRNA but with lesser content of rRNA, tRNA or snoRNA [20]. Therefore, most studies are focused on miRNAs.

Besides membranous vesicles, extracellular miRNAs can also form complex with either argonaute protein or high density lipoprotein (HDL). Vickers et al. found that HDL transported endogenous miRNAs and delivered them to cultured hepatocytes resulted in significant loss of conserved mRNA targets [21]. However, the study by Wagner et al. suggested that HDL could not efficiently deliver the bounded miRNAs to smooth muscle, endothelial and peripheral blood mononuclear cells [22]. Turchinovich and Arroyo et al. showed that extracellular miRNAs were mainly vesicles free and were associated with argonaute 2 protein, a part of RNA-induced silencing complex $[23,24]$. Wang et al. identified nucleophosmin 1 (NPM1) in culture medium from several cell lines as another extracellular miRNA binding protein, which may be involved in both exporting and protecting process of miRNA [25]. However, these extracellular miRNAs were probably by-products of dead cells [24]. Taken together, evidences strongly suggested that the extracellular vesicle may constitute a well-designed pathway for intercellular transfer of miRNA information $[26,27]$.

\section{ExRNAs in renal disease, pathogenesis, diagnosis and therapy}

The stably existence of RNA outside the cells has expanded our knowledge of the role exRNA may play in complex processes. Firstly, the concept that exRNAs represent a novel approach in intercellular signaling that alter the phenotypes of target cells, both locally and at distant sites highlight the transformative capacity that exRNAs may have in regulating physiology and pathology. Then, the exRNAs, especially those release into the urine from epithelial cells facing the urinary space could be representative of the health or disease condition of the urinary system and serve as an ideal source of non-invasive biomarkers for renal dysfunction and injury. Last but not least, therapies targeting exRNAs involved in pathogenesis of kidney diseases and targeted delivery of exRNA-loaded extracellular vesicles (EVs) for gene therapy will be promising therapeutic interventions. Here, we discuss studies published thus far on exRNAs in renal diseases with major findings.

\section{Acute kidney injury}

In a global assessment of circulating miRNA in critically ill patients complicated with acute kidney injury (AKI), Lorenzen et al. identified differently expressed miR-16, miR-320 and miR-210 and concluded that miR-210 was an independently strong predictor of survival [28].

Compared with normal human, urinary miR-494 level was 60-fold higher in patients with AKI. In ischemia/reperfusion (I/R) model, miR-494 in urinary was significantly increased even before the serum creatinine rose. Therefore, MiR-494 may serve as a noninvasive biomarker for AKI. Moreover, miR-494 may inhibit the upregulation of activating transcription factor 3 (ATF3), which contributed to inflammatory or adhesion molecule-induced kidney injury after I/R [29].

Wang et al. demonstrated that urinary but not serum miR-10a and miR-30d may represent sensitive biomarkers for I/R-induced kidney injury and evaluating urinary miRNAs may be potentially high-throughput and noninvasive methods for detecting renal injury [30].

Pavkovic et al. detected more than 20-fold changes for 11 urinary miRNAs in rats with cisplatin [31]. The authors found that these changes may lead to DNA damage response, cell cycle dysregulation and cell apoptosis in cisplatin-induced nephrotoxicity.

Recovery of AKI could be improved by administration of mesenchymal stem cells (MSCs). Microarray analysis of RNAs in extracted microvesicles revealed several cellular mRNAs that were shuttled horizontally by microvesicles. These mRNAs were those associated with mesenchymal phonotype by transcriptional regulation and with control of immunology, which may promote proliferation of surviving tubular cells after injury [32].

Depletion of miRNA in MSCs by Drosha-knockdown resulted in global downregulation of miRNAs in MSCsderived vesicles and markedly reduced their intrinsic potential of regeneration after AKI, which suggested a critical role of exosomal miRNA in recovery in AKI [33].

In ATP-depleted proximal tubular epithelial cells (PTECs) induced by 2-deoxyglucose (2-DG) and antimycin A co-treatment, MSCs-derived EVs mediated miRNAs transfer and was associated with transcriptional regulation of miRNAs in damaged PTECs. These miRNAs were involved in the processes of repair and recovery [34].

Similar findings were described in cisplatin-induced AKI. Insulin growth factor-1 receptor (IGF-1R) mRNA was transfer by MSCs-derived exosomes, which improved sensitivity to IGF-1 and enhanced cell proliferation after cisplatin damage [35].

These studies elucidated that MSC-derived "healing" exRNAs directly potentiated the regenerative capacity of injured tubular cells and promote recovery after AKI. 


\section{Chronic kidney disease / renal fibrosis}

A recent study by Muralidharan et al. characterized the circulating and urinary miRNA pattern associated with reduced glomerular filtration rate (GFR) [36]. Expression of 384 urinary and 266 circulatory miRNAs, such as let-7a, miR-130, miR-1825, miR-1281 and miR-423 were significantly different between patients with estimated GFR $\geq 30$ versus $<30 \mathrm{ml} / \mathrm{min} / 1.73 \mathrm{~m}^{2}$, which is resembled and confirmed by albumin/TGF-beta1 treated mice and TGF-beta1 exposed proximal tubular cells. These fibrosis-associated miRNA may have diagnosis and prognosis utility in chronic kidney disease (CKD). However, the authors did not show the existing forms of these miRNAs in circulation or urine.

Ichii et al. found high levels of miR-146a in urine of B6.MRL-1 mice developing CKD. However, miR146a mainly existed in urine sediments rather than supernatants [37].

Neal et al. measured levels of miRNAs in patients of different stages of CKD including those undergoing maintenance haemodialysis [38]. They found that some miRNAs in circulation were reduced in patients with severe CKD when compared to those with normal renal function or mild renal impairment and suggested using circulating miRNA as biomarkers for CKD.

Circulating EVs, mostly from endothelial cells, platelets and neutrophils have been associated with pathophysiological changes and complications of CKD, such as endothelial dysfunction [39], cardiac and vascular disorders [40-44], coagulation abnormalities [45] and anemia $[45,46]$. However, the compositions of EVs remain largely unknown.

Upregulation of miR-144 in circulating EVs by erythropoietin markedly relieved the disruption of tubular basement membrane, whose integrity is critical against renal fibrosis [47].

TGF-beta1 mRNA was secreted by injured tubular epithelial cells and transported to interstitial fibroblasts through exosomes, which initiate regeneration response against hypoxia [48].

In obstructive renal fibrosis model, secreted miR-21 from injured tubular epithelial cells promote tubular phenotype transition [49]. In the same model, miR-34a was secreted by interstitial fibroblast and transported via microvesicles toward tubular cells, where it induced cell apoptosis and tubular atrophy [50].

The exRNAs-mediated homogeneous and heterogeneous cell-to-cell communication may explain the continuous progression of tubulointerstitial fibrosis regardless of what the original cause is and whether the cause persists.

Future studies need to elucidate the direct evidence concerning the transfer of exRNA-containing EVs in vivo.

\section{Polycystic kidney disease}

Polycystic kidney disease (PKD) is a hereditary disorder in which abnormal cysts develop and grow in kidney. There are two types of PKD, the most common autosomal dominant polycystic kidney disease (ADPKD) and relatively rare autosomal recessive polycystic kidney disease (ARPKD). Ben-Dov et al. found that urine exosomal miR-1 and miR-133 were less abundant in ADPKD patients [51]. Aberrantly expressed miRNAs in cystic kidneys regulate key aspects of cyst pathogenesis such as cyst epithelial cell proliferation and apoptosis as well as dosage of the various cystic kidney disease genes [52] However, whether these secreted miRNAs are involved in the pathogenesis of ADPKD remain unknown.

\section{Diabetic kidney disease}

Wang et al. determined the urinary mRNA levels of extracellular matrix and ELR-CXC chemokine ligand in patients with diabetic nephropathy [53]. Compared with healthy controls, decreased mRNA levels of CXCL10 and CXCL11 and increased mRNA levels of collagen IA1 chain and fibronectin were found in urine of diabetic nephropathy. However, urinary CXCL9 mRNA level was associated with both baseline estimated GFR and the rate of GFR decline, which may be used for risk stratification of diabetic nephropathy.

MiRNA content in urinary exosome is altered in patients of type 1 diabetic with early diabetic kidney disease (DKD) [54]. Urinary exosomes derived from diabetic patients with microalbuminuria have enriched miR-130 and miR-145 and reduced miR-155 and miR424. In streptozosin (STZ) induced animal model of diabetes, urinary miR-145 was also increased in incipient diabetic nephropathy, while overexpression of miR-145 was observed in glomerular mesangial cells.

In type 2 diabetic patients, urinary exosomal miRNA content is markedly varied in patients with versus without DKD [55, 56]. However, different study groups identified different miRNAs, which might be explained by limited patient number and different detection methods.

These urinary exosomal miRNAs may serve as potential biomarkers of DKD.

\section{Lupus nephritis}

Sole et al. showed that miR-29c levels in urine exosomes not in urinary pellet had a negative strong correlation with the histological fibrosis index and glomerular sclerosis in patients with lupus nephritis (LN), suggesting it may be a non-invasive marker [57].

In patients and B6.MRLc1 mice with lupus nephritis, Ichii et al. identified higher level of urinary exosomal miR-26a compared with healthy control [58]. The levels of miR-26a in exosomes were positively correlated with 
urinary protein excretion levels, which may provide a convenient biomarker of lupus nephritis.

\section{Urinary tumor}

Circulating miRNA levels were distinctly increased in renal cell carcinoma (RCC) patients [59]. Only small numbers of miRNAs had tumor-specific origins suggested that multiple factors affected tumor environment. Among 36 up-regulated miRNAs in RCC patients' serum, the authors identified miR-1233 as a potential biomarker for RCC. In another study, lower level of plasma miR-508-3p was observed in RCC patients [60].

Hanke et al. demonstrated that the RNA ratio of miR$126 /$ miR-152 enabled the detection of urothelial bladder cancer from urine [61].

\section{Kidney transplantation}

Differentiation of stable transplant patients with transplant patients with acute rejection is difficult. Lorenzen et al. compared urinary miRNA profiles and identified three markedly dysregulated miRNAs in urine of patients with acute rejection [62]. Among them, the authors found that only urinary miR-210 could be used for differential diagnosis between transplant patients with acute rejection and stable transplant patients with urinary tract infection or transplant patients before or after rejection, suggesting miR-210 as a biomarker for acute kidney rejection.

Peake et al. found the selectivity of mRNA packaging in urine exosomes [63]. After renal transplantation, protein levels of IL-18 and neutrophil gelatinase-associated lipocalin (NGAL) in urine but not mRNA levels of IL-18, NGAL and cystatin $\mathrm{C}$ in urine exosomes reflected the day 7 creatinine reduction ratio (CRR). KIM-1 mRNA remained undetectable in exosome though urinary KIM-1 increased after transplantation. Exosomal mRNA for IL-18, NGAL and cystatin $\mathrm{C}$ was detectable in all CKD patients, but only IL-18 mRNA was increased. Similar as in transplantation, exosomal NGAL mRNA was unchanged in CKD.

\section{Comparison of isolation and detection technique of exRNAs}

Despite the great interest in revealing the role of exRNA in progression of renal diseases and using them as biomarkers, there is no unified methodology for exRNA isolation and detection.

Using density gradient ultracentrifugation could isolate both EVs and HDL particles [64]. Rotor type and centrifugation time also influence the yield and purity of EVs [65]. Cvjetkovic et al. concluded that centrifugation settings should be modified according to different rotors and calculate based on $\mathrm{k}$-factor to pellet particles equally. The regular 70-min-centrifugation time seemed insufficient for isolation of exosomes. Extending the centrifugation time achieved higher vesicle yields. However, centrifugation time beyond $4 \mathrm{~h}$ was not recommended to avoid the contamination of soluble proteins.

Li et al. compared seven exRNA isolation kits. Although all these kits received $\geq 50 \%$ recovery of synthetic RNAs input, mercury-biofluids kit displayed biases in the length of the isolated RNAs. ExRNA yields from plasma differed widely when using different kits, however, contamination of lysis buffer in RNAdvance and MagMAX kits may partly result in the high reading. All kits had different degrees of DNA contaminant. Moreover, differences in RTPCR amplification may due to the presence of RT-PCR inhibitors in some exRNA samples. Most critically, amplification bias for a particular RNA species seemed inevitable when purifying exRNA samples with the majority of kits, such as mRNA-dominant amplification from the QuickRNA sample and miRNA-exclusive amplification from the DirectZol exRNA sample [66].

MiRNAs in biofluids are the most widely used exRNAs in clinical diagnosis and prognosis. Tanriverdi et al. compared four methodologies for miRNA detection from plasma [67]. They identified the best performed in-House RNA isolation Kit. Meanwhile, on high-throughput BioMark platform, the reproducibility of the miScript miRNA Assay technology performed superior to that of the TaqMan miRNA Assay technology.

Recently, the performance of various methods and kits for isolating circulating exRNAs were compared by Guo et al. Among the five different isolation kits, the Circulating Nucleic Acid Kit had the greatest isolation variability but for only miRNA class. Ambion TRIzol generated the largest number of reads mapped to the genome [68].

For EVs isolation, Royo et al. compared five different methods including three commercial kits from NORGEN, ThermoFisher and System Biosciences respectively, ultracentrifugation and a lectin-based purification (LEC), exploiting affinity for glycosylated proteins enriched on the surface of vesicles [69]. MiRNA profiling was possible after EV isolation because urine miRNAs were enriched in urinary EVs. All methods have been equally successful in obtaining a miRNA profile from $10 \mathrm{~mL}$ of frozen-stored urine except for LEC.

Van Deun et al. compared and evaluated 4 exosome isolation protocols and found that OptiPrep density gradient centrifugation outperformed ultracentrifugation and ExoQuick and Total Exosome Isolation precipitation. As for purity, it got the highest yield of nanovesicles with exosomal marker proteins such as CD63 and with less contamination of argonaute 2 [70].

Crossland et al. compared precipitation reagents, RNA isolation kits and ultracentrifugation in EV isolation and RNA extraction from serum or urine samples [71]. For serum EV recovery, the Life Technologies precipitation 
Table 1 Overview of exRNA detection in renal diseases

\begin{tabular}{|c|c|c|c|c|c|}
\hline Disease & Species/Model & Specimen & Type of RNA & Results & References \\
\hline \multirow[t]{8}{*}{$\overline{\mathrm{AKI}}$} & Human & Plasma & miRNA & $\begin{array}{l}\text { Circulating miR- } 210 \text { predicts mortality of critically } \\
\text { ill patients with AKI. }\end{array}$ & {$[28]$} \\
\hline & Human/mice (I/R) & Urine & miRNA & $\begin{array}{l}\text { Urinary levels of miRNA-494 increased significantly } \\
\text { before the rise in serum creatinine. }\end{array}$ & [29] \\
\hline & Mice (I/R) & Urine/serum & miRNA & $\begin{array}{l}\text { Levels of urinary miR-10a and miR-30d were positively } \\
\text { correlated with the degree of kidney injury induced } \\
\text { by renal I/R. }\end{array}$ & {$[30]$} \\
\hline & Rat (Cisplatin) & Urine & miRNA & $\begin{array}{l}\text { Eleven miRNAs were markedly changed in profiling } \\
\text { experiment, which were involved with cisplatin- } \\
\text { induced nephrotoxicity. }\end{array}$ & [31] \\
\hline & Mice (glycerol) & Blood & mRNA & $\begin{array}{l}\text { MRNA from MSCs accelerated the morphologic } \\
\text { and functional recovery of glycerol-induced AKI by } \\
\text { inducing proliferation of tubular cells. }\end{array}$ & {$[32]$} \\
\hline & Mice (glycerol) & Blood & miRNA & $\begin{array}{l}\text { MiRNA depletion in MSCs significantly reduced } \\
\text { their intrinsic regenerative potential in AKI. }\end{array}$ & [33] \\
\hline & In vitro (ATP depletion) & Blood & miRNA & $\begin{array}{l}\text { MiRNAs from MSCs were involved in recovery } \\
\text { process in PTECs. }\end{array}$ & {$[34]$} \\
\hline & In vitro (Cisplatin) & Blood & mRNA & $\begin{array}{l}\text { Transfer of IGF-1R mRNA from MSCs to cisplatin } \\
\text { damaged proximal tubular cells increased cell } \\
\text { proliferation. }\end{array}$ & [35] \\
\hline \multirow[t]{6}{*}{ CKD/fibrosis } & $\begin{array}{l}\text { Human/Mice (Alb/TGF-beta) } \\
\text { /In vitro (TGF-beta1) }\end{array}$ & Plasma/Urine & miRNA & $\begin{array}{l}\text { Specific urinary and plasma miRNA profile, such } \\
\text { as Let-7a, miR-130a, miR-1825, miR-1281 and miR- } \\
423 \text { were associated with declined eGFR and renal } \\
\text { fibrosis. }\end{array}$ & [36] \\
\hline & Human & Blood/Urine & miRNA & $\begin{array}{l}\text { Circulating levels of total and specific miRNAs } \\
\text { were reduced in patients with severe CKD and } \\
\text { strongly correlated with eGFR. }\end{array}$ & [38] \\
\hline & Mice (obstructive renal fibrosis) & Blood & miRNA & $\begin{array}{l}\text { Bone marrow derived miR-144 protected the } \\
\text { integrity of tubular basement membrane by inhibiting } \\
\text { the activation of the tPA/MMP9-mediated proteolytic } \\
\text { network. }\end{array}$ & {$[47]$} \\
\hline & Mice (obstructive renal fibrosis) & Kidney & mRNA & $\begin{array}{l}\text { TGF-beta1 mRNA from injured epithelial cells constituted } \\
\text { a rapid response to initiate tissue repair/regenerative } \\
\text { responses and activation of fibroblasts. }\end{array}$ & [48] \\
\hline & Mice (obstructive renal fibrosis) & Kidney & miRNA & $\begin{array}{l}\text { MiR-21 from injured tubular cells targeted PTEN } \\
\text { protein and enhanced Akt signaling in recipient } \\
\text { tubular cells. }\end{array}$ & [49] \\
\hline & Mice (obstructive renal fibrosis) & Kidney & miRNA & $\begin{array}{l}\text { Secreted fibroblast miR-34a induced tubular cell } \\
\text { apoptosis by targeting } \mathrm{Bcl}-2 \text { protein. }\end{array}$ & {$[50]$} \\
\hline PKD & Human & Urine & miRNA & $\begin{array}{l}\text { Urinary miR-1, miR-133, miR-223 and miR-199 were } \\
\text { dysregulated in ADPKD when compared to other } \\
\text { CKD. }\end{array}$ & [51] \\
\hline \multirow[t]{4}{*}{ DKD } & Human & Urine & mRNA & $\begin{array}{l}\text { Urinary mRNA levels of CXCL9 and CXCL11 correlated } \\
\text { with baseline eGFR. Urinary CXCL9 mRNA level was } \\
\text { independently associated with the rate of GFR decline. }\end{array}$ & {$[53]$} \\
\hline & Human/Mice (STZ) & Urine & miRNA & $\begin{array}{l}\text { Urinary exosomal miRNA content is enriched in } \\
\text { type } 1 \text { diabetic patients with incipient diabetic } \\
\text { nephropathy. }\end{array}$ & {$[54]$} \\
\hline & Human & Urine & miRNA & $\begin{array}{l}\text { Urinary exosomal miR-320c and miR-6068 were } \\
\text { altered in type } 2 \text { diabetic patients with DKD. }\end{array}$ & {$[55]$} \\
\hline & Human & Urine & miRNA & $\begin{array}{l}\text { Urinary extracellular vesicle miR-192 may discriminate } \\
\text { the normoalbuminuric group from the microalbuminuric } \\
\text { group of type } 2 \text { diabetes patients. }\end{array}$ & {$[56]$} \\
\hline LN & Human & Urine & miRNA & $\begin{array}{l}\text { MiR-29c levels in urinary exosomes showed a } \\
\text { negatively strong correlation with the histological } \\
\text { chronicity index and glomerular sclerosis in patients } \\
\text { with LN. }\end{array}$ & {$[57]$} \\
\hline
\end{tabular}


Table 1 Overview of exRNA detection in renal diseases (Continued)

\begin{tabular}{|c|c|c|c|c|c|}
\hline Disease & Species/Model & Specimen & Type of RNA & Results & References \\
\hline & $\begin{array}{l}\text { Human/Mice (autoimmune } \\
\text { glomerulonephritis) }\end{array}$ & Urine & miRNA & $\begin{array}{l}\text { Urinary exosomes miR-26a levels in B6.MRLc1 and } \\
\text { patients with lupus nephritis were significantly } \\
\text { higher compared with those for the respective } \\
\text { healthy control. }\end{array}$ & [58] \\
\hline \multirow[t]{3}{*}{ Tumor } & Human & Serum & miRNA & MiR-1233 was increased in serum of RCC patients. & [59] \\
\hline & Human & Blood & miRNA & $\begin{array}{l}\text { The level of plasma miR-508-3p in RCC patients } \\
\text { was significantly different from that in control. }\end{array}$ & [60] \\
\hline & Human & Urine & miRNA & $\begin{array}{l}\text { The RNA ratio of miRNA-126: miRNA-152 in urine } \\
\text { enabled the detection of urothelial bladder cancer. }\end{array}$ & [61] \\
\hline \multirow[t]{2}{*}{ Transplantation } & Human & Urine & miRNA & $\begin{array}{l}\text { The urinary miR-210 level identified patients with } \\
\text { acute rejection and predicted long-term kidney } \\
\text { function. }\end{array}$ & [62] \\
\hline & Human & Urine & mRNA & $\begin{array}{l}\text { Urinary exosomal IL-18 mRNA was increased in } \\
\text { CKD after transplantation. }\end{array}$ & [63] \\
\hline
\end{tabular}

AKI Acute kidney injury, I/R Ischemia/reperfusion, MSC Mesenchymal stem cell, CKD Chronic kidney disease, Alb Albumin, TGF-beta Transforming growth factorbeta, eGFR Estimated glomerular filtration rate, $t P A$ Tissue plasminogen activator, MMP9 Matrix metallopeptidase 9, PTEN Phosphatase and tensin homolog, Bcl-2 Bcell lymphoma 2, PKD Polycystic kidney disease, ADPKD Autosomal dominant polycystic kidney disease, DKD Diabetic kidney disease, CXCL C-X-C motif chemokine ligand, STZ Streptozosin, LN Lupus nephritis, RCC Renal cell carcinoma

reagent was superior to SBI reagent. For urine EV isolation, the NB Urine Exosome RNA Isolation Kit improved the results compared to ultracentrifugation. For serum EV RNA concentration, the Qiagen miRNeasy ${ }^{\mathrm{TM}}$ RNA isolation kit was most suitable than any other kits.

Robust qRT-PCR analysis of miRNA levels in EVs is controversial, as the absence of cellular endogenous controls. Crossland et al. further evaluated suitable endogenous normalization controls for qRT-PCR analysis. Among the 8 candidates, small RNAs HY3 and RUN48 were selected as optimal controls for urine studies, while HY3 and U6 were identified as suitable for serum extracellular miRNA expression assessments [71].

\section{Summary}

In this review, we summarized that exRNAs have functional, diagnostic and therapeutic roles in renal diseases (Table 1). However, key challenges remain. Despite well described in vitro, it is difficult to prove the functional significance of exRNA in vivo. Isolation and detection techniques need improvement. A systematic analysis and comparison of exRNAs in bodily fluids of healthy individuals and patients along with a better understanding of regulation of exRNA secretion, carriers of exRNAs, mechanism of targeting and effector function in target cells will generate opportunities to insight into the pathophysiology of kidney injury and identify novel strategies for diagnosis, prognosis and treatment of renal diseases.

\section{Abbreviations}

2-DG: 2-deoxyglucose; ADPKD: Autosomal dominant polycystic kidney disease; AKI: Acute kidney injury; ARPKD: Autosomal recessive polycystic kidney disease; ATF3: Activating transcription factor 3; CKD: Chronic kidney disease; CRR: Creatinine reduction ratio; DKD: Diabetic kid ney disease; EVs: Extracellular vesicles; exRNA: Extracellular RNA; HDL: High density lipoprotein; I/R: Ischemia/ reperfusion; IGF-1R: Insulin growth factor-1 receptor; LEC: Lectin-based purification; LN: Lupus nephritis; IncRNA: Long non-coding RNA; miR: MicroRNA; miRNA: MicroRNA; mRNA: Messenger RNA; MSCs: Mesenchymal stem cells; MVBs: Multivesicular bodies; NGAL: Neutrophil gelatinase-associated lipocalin; NPM1: Nucleophosmin 1; piRNAs: Piwi-interacting RNA; PKD: Polycystic kidney disease; PTECs: Proximal tubular epithelial cells; RCC: Renal cell carcinoma; siRNA: Small interfering RNA; snoRNA: Small nucleolar RNA; STZ: Streptozosin; tRNA: Transfer RNA

Acknowledgements

Not applicable.

Funding

This work was supported by Key Program of National Natural Science Foundation of China 81530022, General Program of National Natural Science Foundation of China 81873618, 81470971 and National Natural Science Foundation for Young Scholars of China 81600526.

Availability of data and materials Not applicable.

\section{Authors' contributions}

YZ was a major contributor in writing the manuscript. JY contributed in writing and revising the manuscript. All authors read and approved the final manuscript.

Ethics approval and consent to participate

Not applicable.

Consent for publication

Not applicable.

Competing interests

The authors declare that they have no competing interests.

\section{Publisher's Note}

Springer Nature remains neutral with regard to jurisdictional claims in published maps and institutional affiliations.

Received: 1 March 2017 Accepted: 27 December 2018

Published online: 14 February 2019

References

1. Chen $X$, et al. Characterization of microRNAs in serum: a novel class of biomarkers for diagnosis of cancer and other diseases. Cell Res. 2008;18(10): 997-1006. 
2. Menke TB, Warnecke JM. Improved conditions for isolation and quantification of RNA in urine specimens. Ann N Y Acad Sci. 2004;1022: 185-9.

3. Michael $A$, et al. Exosomes from human saliva as a source of microRNA biomarkers. Oral Dis. 2010;16(1):34-8.

4. Kosaka N, et al. MicroRNA as a new immune-regulatory agent in breast milk. Silence. 2010;1(1):7.

5. Zubakov D, et al. MicroRNA markers for forensic body fluid identification obtained from microarray screening and quantitative RT-PCR confirmation. Int J Legal Med. 2010;124(3):217-26.

6. Hanson EK, Lubenow H, Ballantyne J. Identification of forensically relevant body fluids using a panel of differentially expressed microRNAs. Anal Biochem. 2009;387(2):303-14.

7. Freedman JE, et al. Diverse human extracellular RNAs are widely detected in human plasma. Nat Commun. 2016:7:11106.

8. Crescitelli R, et al. Distinct RNA profiles in subpopulations of extracellular vesicles: apoptotic bodies, microvesicles and exosomes. J Extracell Vesicles. 2013;2. https://doi.org/10.3402/jev.v2i0.20677.

9. Colombo M, Raposo G, Thery C. Biogenesis, secretion, and intercellular interactions of exosomes and other extracellular vesicles. Annu Rev Cell Dev Biol. 2014:30:255-89.

10. Valadi $\mathrm{H}$, et al. Exosome-mediated transfer of mRNAs and microRNAs is a novel mechanism of genetic exchange between cells. Nat Cell Biol. 2007; 9(6):654-9.

11. Nolte-'t Hoen EN, et al. Deep sequencing of RNA from immune cell-derived vesicles uncovers the selective incorporation of small non-coding RNA biotypes with potential regulatory functions. Nucleic Acids Res. 2012;40(18): 9272-85.

12. Skog J, et al. Glioblastoma microvesicles transport RNA and proteins that promote tumour growth and provide diagnostic biomarkers. Nat Cell Biol. 2008;10(12):1470-6.

13. Simons M, Raposo G. Exosomes--vesicular carriers for intercellular communication. Curr Opin Cell Biol. 2009;21(4):575-81.

14. Gibbings DJ, et al. Multivesicular bodies associate with components of miRNA effector complexes and modulate miRNA activity. Nat Cell Biol. 2009; 11(9):1143-9.

15. Lee YS, et al. Silencing by small RNAs is linked to endosomal trafficking. Nat Cell Biol. 2009;11(9):1150-6.

16. Trajkovic $\mathrm{K}$, et al. Ceramide triggers budding of exosome vesicles into multivesicular endosomes. Science. 2008;319(5867):1244-7.

17. Kosaka N, et al. Secretory mechanisms and intercellular transfer of microRNAs in living cells. J Biol Chem. 2010;285(23):17442-52.

18. Mittelbrunn $\mathrm{M}$, et al. Unidirectional transfer of microRNA-loaded exosomes from T cells to antigen-presenting cells. Nat Commun. 2011;2:282.

19. Kajimoto $T$, et al. Ongoing activation of sphingosine 1-phosphate receptors mediates maturation of exosomal multivesicular endosomes. Nat Commun. 2013:4:2712

20. Ben-Dov IZ, et al. Cell and microvesicle urine microRNA deep sequencing profiles from healthy individuals: observations with potential impact on biomarker studies. PLoS One. 2016;11(1):e0147249.

21. Vickers KC, et al. MicroRNAs are transported in plasma and delivered to recipient cells by high-density lipoproteins. Nat Cell Biol. 2011; 13(4):423-33.

22. Wagner J, et al. Characterization of levels and cellular transfer of circulating lipoprotein-bound microRNAs. Arterioscler Thromb Vasc Biol. 2013;33(6): 1392-400.

23. Arroyo JD, et al. Argonaute2 complexes carry a population of circulating microRNAs independent of vesicles in human plasma. Proc Natl Acad Sci U S A. 2011;108(12):5003-8.

24. Turchinovich A, et al. Characterization of extracellular circulating microRNA. Nucleic Acids Res. 2011;39(16):7223-33.

25. Wang $K$, et al. Export of microRNAs and microRNA-protective protein by mammalian cells. Nucleic Acids Res. 2010;38(20):7248-59.

26. Chen $X$, et al. Secreted microRNAs: a new form of intercellular communication. Trends Cell Biol. 2012;22(3):125-32.

27. Chen $X$, et al. Horizontal transfer of microRNAs: molecular mechanisms and clinical applications. Protein Cell. 2012;3(1):28-37.

28. Lorenzen JM, et al. Circulating miR-210 predicts survival in critically ill patients with acute kidney injury. Clin J Am Soc Nephrol. 2011;6(7):1540-6.

29. Lan YF, et al. MicroRNA-494 reduces ATF3 expression and promotes AKI. J Am Soc Nephrol. 2012;23(12):2012-23.
30. Wang $\mathrm{N}$, et al. Urinary microRNA-10a and microRNA-30d serve as novel, sensitive and specific biomarkers for kidney injury. PLoS One. 2012;7(12):e51140.

31. Pavkovic M, Riefke B, Ellinger-Ziegelbauer H. Urinary microRNA profiling for identification of biomarkers after cisplatin-induced kidney injury. Toxicology. 2014;324:147-57.

32. Bruno S, et al. Mesenchymal stem cell-derived microvesicles protect against acute tubular injury. J Am Soc Nephrol. 2009;20(5):1053-67.

33. Collino F, et al. AKI recovery induced by mesenchymal stromal cell-derived extracellular vesicles carrying MicroRNAs. J Am Soc Nephrol. 2015;26(10): 2349-60.

34. Lindoso RS, et al. Extracellular vesicles released from mesenchymal stromal cells modulate miRNA in renal tubular cells and inhibit ATP depletion injury. Stem Cells Dev. 2014;23(15):1809-19.

35. Tomasoni $\mathrm{S}$, et al. Transfer of growth factor receptor mRNA via exosomes unravels the regenerative effect of mesenchymal stem cells. Stem Cells Dev. 2013:22(5):772-80

36. Muralidharan J, et al. Extracellular microRNA signature in chronic kidney disease. Am J Physiol Renal Physiol. 2017. https://doi.org/10.1152/ajprenal. 00569.2016.

37. Ichii $\mathrm{O}$, et al. Altered expression of microRNA miR-146a correlates with the development of chronic renal inflammation. Kidney Int. 2012;81(3):280-92.

38. Neal CS, et al. Circulating microRNA expression is reduced in chronic kidney disease. Nephrol Dial Transplant. 2011;26(11):3794-802

39. Merino A, et al. Effect of different dialysis modalities on microinflammatory status and endothelial damage. Clin J Am Soc Nephrol. 2010;5(2):227-34.

40. Amabile $\mathrm{N}$, et al. Circulating endothelial microparticles are associated with vascular dysfunction in patients with end-stage renal failure. J Am Soc Nephrol. 2005;16(11):3381-8

41. Amabile $\mathrm{N}$, et al. Predictive value of circulating endothelial microparticles for cardiovascular mortality in end-stage renal failure: a pilot study. Nephrol Dial Transplant. 2012;27(5):1873-80.

42. Soriano $\mathrm{S}$, et al. Endothelial damage and vascular calcification in patients with chronic kidney disease. Am J Physiol Renal Physiol. 2014;307(11): F1302-11.

43. Buendia $P$, et al. Endothelial microparticles mediate inflammation-induced vascular calcification. FASEB J. 2015;29(1):173-81.

44. Dursun I, et al. The relationship between circulating endothelial microparticles and arterial stiffness and atherosclerosis in children with chronic kidney disease. Nephrol Dial Transplant. 2009;24(8):2511-8.

45. Farag $\mathrm{YM}$, et al. Modulation of platelet activation in chronic kidney disease patients on erythropoiesis-stimulating agents. Clin Appl Thromb Hemost. 2012:18(5):453-61.

46. Daniel $\mathrm{L}$, et al. Increase of circulating neutrophil and platelet microparticles during acute vasculitis and hemodialysis. Kidney Int. 2006;69(8):1416-23.

47. Zhou Y, et al. Erythropoietin protects the tubular basement membrane by promoting the bone marrow to release extracellular vesicles containing tPA-targeting miR-144. Am J Physiol Renal Physiol. 2016;310(1):F27-40.

48. Borges FT, et al. TGF-beta1-containing exosomes from injured epithelial cells activate fibroblasts to initiate tissue regenerative responses and fibrosis. J Am Soc Nephrol. 2013:24(3):385-92.

49. Zhou $Y$, et al. miR-21-containing microvesicles from injured tubular epithelial cells promote tubular phenotype transition by targeting PTEN protein. Am J Pathol. 2013;183(4):1183-96.

50. Zhou Y, et al. Secreted fibroblast-derived miR-34a induces tubular cell apoptosis in fibrotic kidney. J Cell Sci. 2014;127(Pt 20):4494-506.

51. Ben-Dov IZ, et al. Urine microRNA as potential biomarkers of autosomal dominant polycystic kidney disease progression: description of miRNA profiles at baseline. PLoS One. 2014;9(1):e86856.

52. Hajarnis S, Lakhia R, Patel V. MicroRNAs and polycystic kidney disease; 2015.

53. Wang $G$, et al. Urinary mRNA levels of ELR-negative CXC chemokine ligand and extracellular matrix in diabetic nephropathy. Diabetes Metab Res Rev. 2015;31(7):699-706.

54. Barutta F, et al. Urinary exosomal microRNAs in incipient diabetic nephropathy. PLoS One. 2013;8(11):e73798.

55. Delic D, et al. Urinary Exosomal miRNA signature in type II diabetic nephropathy patients. PLoS One. 2016;11(3):e0150154.

56. Jia Y, et al. miRNAs in Urine Extracellular Vesicles as Predictors of Early-Stage Diabetic Nephropathy. J Diabetes Res. 2016;2016:7932765.

57. Sole C, et al. miR-29c in urinary exosomes as predictor of early renal fibrosis in lupus nephritis. Nephrol Dial Transplant. 2015;30(9):1488-96. 
58. Ichii O, et al. Decreased miR-26a expression correlates with the progression of podocyte injury in autoimmune glomerulonephritis. PLoS One. 2014; 9(10):e110383.

59. Wulfken $L M$, et al. MicroRNAs in renal cell carcinoma: diagnostic implications of serum miR-1233 levels. PLoS One. 2011;6(9):e25787.

60. Zhai Q, et al. Identification of miR-508-3p and miR-509-3p that are associated with cell invasion and migration and involved in the apoptosis of renal cell carcinoma. Biochem Biophys Res Commun. 2012;419(4):621-6.

61. Hanke $M$, et al. A robust methodology to study urine microRNA as tumor marker: microRNA-126 and microRNA-182 are related to urinary bladder cancer. Urol Oncol. 2010;28(6):655-61.

62. Lorenzen JM, et al. Urinary miR-210 as a mediator of acute T-cell mediated rejection in renal allograft recipients. Am J Transplant. 2011;11(10):2221-7.

63. Peake PW, et al. A comparison of the ability of levels of urinary biomarker proteins and exosomal mRNA to predict outcomes after renal transplantation. PLoS One. 2014;9(2):e98644.

64. Yuana Y, et al. Co-isolation of extracellular vesicles and high-density lipoproteins using density gradient ultracentrifugation. J Extracell Vesicles. 2014;3. https://doi.org/10.3402/jev.v3.23262.

65. Cvjetkovic A, Lotvall J, Lasser C. The influence of rotor type and centrifugation time on the yield and purity of extracellular vesicles. J Extracell Vesicles. 2014;3. https://doi.org/10.3402/jev.v3.23111.

66. Li X, Mauro M, Williams Z. Comparison of plasma extracellular RNA isolation kits reveals kit-dependent biases. Biotechniques. 2015:59(1):13-7.

67. Tanriverdi $\mathrm{K}$, et al. Comparison of RNA isolation and associated methods for extracellular RNA detection by high-throughput quantitative polymerase chain reaction. Anal Biochem. 2016;501:66-74.

68. Guo Y, et al. Comprehensive evaluation of extracellular small RNA isolation methods from serum in high throughput sequencing. BMC Genomics. 2017; 18(1):50.

69. Royo F, et al. Comparative miRNA analysis of urine extracellular vesicles isolated through five different methods. Cancers (Basel). 2016;8:12.

70. Van Deun J, et al. The impact of disparate isolation methods for extracellular vesicles on downstream RNA profiling. J Extracell Vesicles. 2014; 3. https://doi.org/10.3402/jev.v3.24858.

71. Crossland RE, et al. Evaluation of optimal extracellular vesicle small RNA isolation and aRT-PCR normalisation for serum and urine. J Immunol Methods. 2016;429:39-49.

Ready to submit your research? Choose BMC and benefit from:

- fast, convenient online submission

- thorough peer review by experienced researchers in your field

- rapid publication on acceptance

- support for research data, including large and complex data types

- gold Open Access which fosters wider collaboration and increased citations

- maximum visibility for your research: over $100 \mathrm{M}$ website views per year

At $\mathrm{BMC}$, research is always in progress.

Learn more biomedcentral.com/submissions 